\title{
Priapism as a Debut Presentation of Chronic Myeloid Leukemia
}

\author{
Jahnvi Dhar1,2, Garvit Chhabra1, Lokesh Khandelwal1,2, Akshee Batra1 and Naresh Gupta1,2
}

\begin{abstract}
Chronic myeloid leukemia (CML) is a chronic myeloproliferative disorder that usually presents with high white blood cell counts and massive splenomegaly. Priapism is a rare manifestation of CML and is mostly due to hyperleukocytosis. Its debut appearance as a sign of hematological dyscrasia is a rare event. Priapism occurring in a setting of any leukemia is both a medical and a urological emergency that requires immediate local therapy, symptomatic treatment, cytoreductive therapy and early initiation of targeted therapy. This case report describes priapism as an unusual presentation of CML and its importance in the work-up and management of patients presenting with priapism.
\end{abstract}

Key Words: Chronic myeloid leukemia, Priapism, Winter's procedure, Chemotherapy.

\section{INTRODUCTION}

Priapism is an involuntary, prolonged and persistent painful penile erection without any sexual arousal or stimulation. Priapism is divided into 2 types: ischemic and non-ischemic. Non-ischemic priapism is due to pelvic or genital trauma that leads to arteriovenous fistula of the penile circulation. Ischemic priapism accounts for most of the cases of priapism. ${ }^{1}$ Sickle cell disease accounts for most cases of ischemic priapism in pediatric population. In adults, most cases are, however, idiopathic. About $20 \%$ of all priapism cases are caused due to hematological disorders. Priapism may occur in patients with hyperleukocytosis and its incidence in adult leukemic patients is $1-5 \%$. Chronic myeloid leukemia (CML) accounts for $50 \%$ of all leukemia cases with priapism.1,2 Being an emergency, early diagnosis and prompt treatment is of paramount importance for restoring organ function.

\section{CASE REPORT}

A 52-year man presented to the emergency with chief complaints of involuntary, prolonged, painful penile erection for four hours. He had no previous history of trauma, intake of new medications, fever, early satiety, abdominal distension and weight loss.

On examination, his vitals were stable with presence of pallor. On per-abdomen examination, he had a massive splenomegaly of $8 \mathrm{~cm}$ below the left costal margin along with hepatomegaly of $3 \mathrm{~cm}$ below right costal margin. On local examination, the penis was erect, along with

1 Department of Medicine, Maulana Azad Medical College, New Delhi, India

2 Department of Medicine, Lok Nayak Hospital, New Delhi, India

Correspondence: Dr. Garvit Chhabra, Department of Medicine, Maulana Azad Medical College, New Delhi-110002, India E-mail: garvit.chhabra26@gmail.com

Received: May 02, 2018; Accepted: August 16, 2018 tenderness and superficial venous engorgement. Rest of the general physical and systemic examinations yielded no significant findings. Immediately on presentation, needle aspiration was performed, but there was no improvement. Then, Winter's procedure (shunting between the engorged corpora cavernosa and the corpus spongiosum of the glans penis) was done. Simultaneously, the complete blood count of the patient showed a hemoglobin of $8.9 \mathrm{gm} / \mathrm{dl}$ with a total leucocyte count of $239 \times 10^{9} / \mathrm{L}$ and platelet count of $625 \times 10^{9} / \mathrm{L}$. His peripheral smear was suggestive of left sided granulopoiesis with granulocytic precursors (myelocytes and metamyelocytes $47 \%$ ) and $4 \%$ blasts (Figure 1). Bone marrow biopsy, which was done at the time of presentation, confirmed the findings of $\mathrm{CML}$ in the chronic phase (Figure 2). BCR-ABL translocation was sent and turned out to be positive. These findings confirmed the underlying hematological malignancy to be CML and the patient was started on hydroxyurea $500 \mathrm{mg}$ TDS, Imatinib $400 \mathrm{mg}$ OD along with Allopurinol $300 \mathrm{mg} \mathrm{OD}$, and adequate hydration. Patient's WBC count started falling and by the third day, the patient became symptomatically better, and his total leucocyte

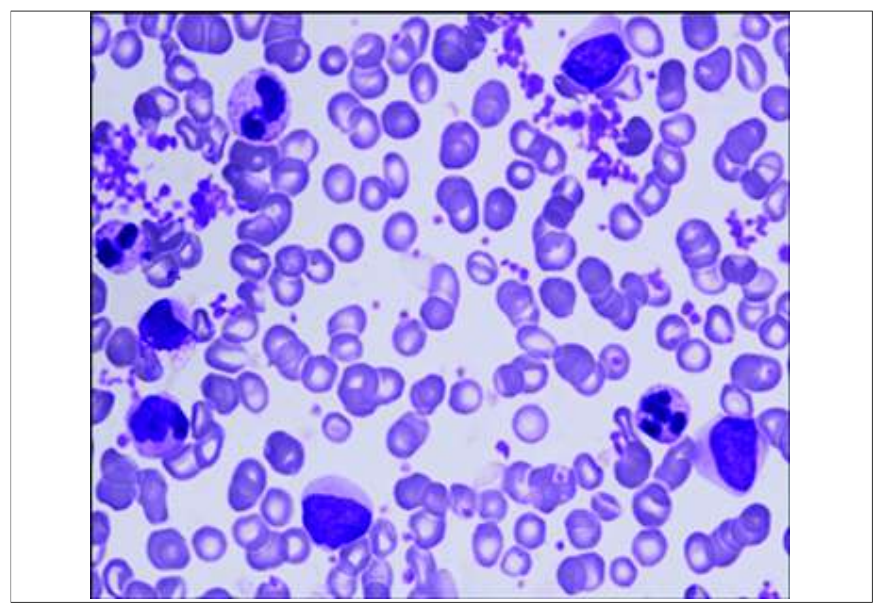

Figure 1: Peripheral smear showing leukocytosis with the myeloid precursor cells. Thrombocytosis, basophilia and eosinophilia are also seen. Blasts are $<10 \%$. 


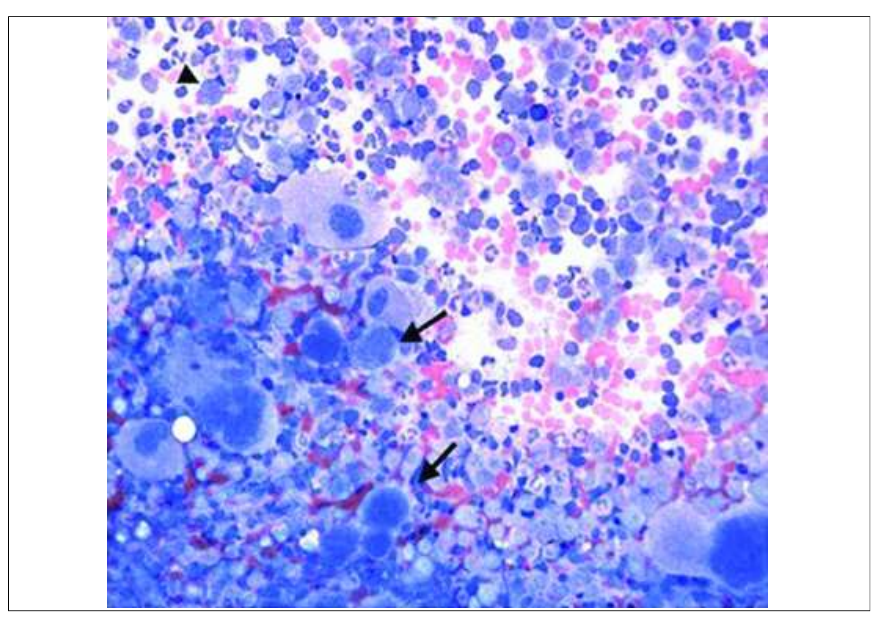

Figure 2: Bone Marrow Aspirate of CML-CHRONIC PHASE (magnification $x 10)$ showing hypercellular bone marrow with predominant granulopoiesis. Occasional blasts can be seen (arrowhead). Sheets and clusters of megakaryocytes and micromegakaryocytes are present (arrows).

count fell to $40 \times 10 \% / \mathrm{L}$ after five days of treatment. Follow-up after one month revealed total leucocyte count of $9 \times 10^{9} / \mathrm{L}$, penile softening and complete improvement of priapism with no complaints of sexual dysfunction.

\section{DISCUSSION}

CML patients usually present with vague symptoms like weight loss, fever, night sweats, bone pain, abdominal pain and fullness. Some patients with $\mathrm{CML}$ can have symptoms related to leukostasis like thromboembolic phenomenon, hearing loss, priapism and neurologic deficits. Rarely, priapism can be the sole presenting complaint in all hematological malignancies and CML accounts for as much as half of them.

Priapism is usually classified as high flow (non-ischemic) and low flow (ischemic) types. Low flow priapism is the most common type and is a urological emergency. It occurs due to venous pooling and congestion of corpora cavernosa, which can be secondary to deposition of leukemic cells in the dorsal veins and the corpora cavernosa of penis. Alternatively, it might be due to leukemic infiltration of the sacral nerves or CNS. ${ }^{3}$ It can lead to irreversible damage, fibrosis and loss of organ function, if treatment is delayed for more than 24 hours.
High flow or arterial priapism usually follows penile or perineal trauma that results in fistula between cavernosal artery and corpus cavernosum, leading to increased arterial inflow into the cavernosal sinusoids.3,4

Priapism may occur at any age; however, two peaks in age distribution have been established. A peak at 5-10 years is noted owing to sickle cell disease. The second peak tends to occur in 20-50 years age. ${ }^{4}$ Some of the causes of priapism include leukemia, trauma, sickle cell anemia, thalassemia, fabry disease, dialysis, vasculitis, fat embolism, spinal cord stenosis, autonomic neuropathy, cauda equine compression, metastasis to the penis or various malignancies, certain pharmacologic agents; and rare causes include amyloidosis, black widow spider bites, and mycoplasma pneumonia infection. Most cases of priapism are idiopathic (64\%) and around $20 \%$ can be attributed to hematologic disorders. ${ }^{4,5}$

A review of literature (Table I), 6-9 is mentioned below highlighting case reports in which priapism led to the diagnosis of CML, and various treatment modalities that were subsequently undertaken. Cases outlining prolonged priapism (24- 48 hours) and/or failed surgical intervention had a higher occurrence of post-treatment organ dysfunction. We have excluded pediatric population, case series, and case reports in any other foreign language.

Differentiating between ischemic and non-ischemic priapism is of paramount importance because of different line of management of the two. It can be achieved by a detailed history, physical examination, corpora cavernosa blood gas analysis, and doppler ultrasound of the penis.3,4 Physical examination in patients with low-flow priapism usually yields a painful and rigid penile shaft but a soft glans; whereas, partially rigid and painless penis characterises high-flow priapism. Intra-cavernosal blood gas analysis aids in differentiating high and low flow priapism. Normal blood gas analysis values indicate high-flow priapism. Doppler ultrasonography can further aid in detecting an arterialto-cavernosal fistula in high-flow priapism patients. Besides this, the work up should also include complete blood count, coagulopathy state, and drugs screen, if indicated.

Table I: Case reports of priapism leading to the diagnosis of chronic myeloid leukemia.

\begin{tabular}{l|c|c|c|l|l}
\hline $\begin{array}{l}\text { Authors } \\
\text { (Y/N) }\end{array}$ & Age (years) & Painful priapism & $\begin{array}{c}\text { Duration of the } \\
\text { complaint }\end{array}$ & $\begin{array}{l}\text { Treatment received } \\
\text { (Y/N) }\end{array}$ & $\begin{array}{c}\text { Post treatment } \\
\text { sexual dysfunction }\end{array}$ \\
\hline Shaeer OK et al.6 & 21 & $\mathrm{Y}$ & 4 days & Failed aspiration, Imatinib, penile prosthesis & $\mathrm{Y}$ \\
\hline Yoshida et al.7 & 29 & $\mathrm{Y}$ & 2 days & $\begin{array}{l}\text { Failed aspiration, glans-cavernosal shunt } \\
\text { (Winter procedure), Imatinib }\end{array}$ & $\mathrm{N}$ \\
\hline llais Tazi & 33 & $\mathrm{Y}$ & 22 hours & Aspiration, Imatinib & $\mathrm{N}$ \\
\hline Meng-Wei Chang et al. & 21 & $\mathrm{Y}$ & 19 hours & $\begin{array}{l}\text { Aspiration and decompression, interferon alfa-2a } \\
(6 \text { MIU/vial), allpurinol }\end{array}$ & $\mathrm{N}$ \\
\hline Ergenc H et al.5 & 19 & $\mathrm{Y}$ & 18 hours & Imatinib, leukapheresis & $\mathrm{N}$ \\
\hline Rojas B et al.9 & 22 & $\mathrm{Y}$ & 36 hours & Leukapheresis, surgical intervention & $\mathrm{Y}$ \\
\hline Nerli RB et al. 2 & 19 & $\mathrm{Y}$ & 24 hours & Irrigation and decompression & $\mathrm{N}$ \\
\hline
\end{tabular}


Sparse literature is available to outline a definitive treatment in cases of priapism with underlying hematological malignancy. However, American Urological Association recommends that systemic treatment of an underlying disorder should only be undertaken after administering intra-cavernous treatment for priapism. It may be relieved by immediate aspiration along with an injection of alpha adrenergics such as phenylephrine or epinephrine. In case of prolonged erection, surgical shunt must be considered. In cases of leukemia, cytoreductive therapy remains the cornerstone in the management of priapism. 10

In this case report, the patient made a complete recovery and had no long term sexual dysfunction owing to a timely diagnosis along with the combined use of surgical intervention for priapism and oncological treatment of underlying $\mathrm{CML}$.

The importance of timely diagnosis and prompt treatment of priapism, with discussion of the management of the case with review of literature, has been emphasised in the above case report; as there is definite incidence of sexual dysfunction following prolonged priapism. Besides providing initial relief of priapism, the further workup and management of the underlying cause, especially a hematological malignancy, is very crucial.

In conclusion, priapism as a debut presentation in CML is very uncommon and all physicians should be aware of this entity for early intervention and management.

\section{REFERENCES}

1. Van der Horst C, Stuebinger H, Seif C, Melchior D, MartínezPortillo FJ, Juenemann KP. Priapism - Etiology, pathophysiology and management. Int Braz J Urol 2003; 29:391-400.

2. Nerli RB, Magdum PV, Hiremath SC, Patil AY, Pai SV, Handigund RS, et al. Priapism - A rare presentation in chronic myeloid leukemia: Case Report. Urol Case Rep 2015; 30:8-10.

3. Chang MW, Tang CC, Chang SS. Priapism - a rare presentation in chronic myeloid leukemia: case report and review of the literature. Chang Gung Med J 2003; 26:288-92.

4. Ekeke ON, Omunakwe HE, Eke N. Management of priapism in adult men. Int Surg 2015; 100:552-7.

5. Ergenc H, Varim C, Karacaer C, Çekdemir D. Chronic myeloid leukemia presented with priapism: Effective management with prompt leukapheresis. Niger J Clin Pract 2015; 18:828-30.

6. Shaeer OKZM, Shaeer KZM, Abdel-Rahman IFS, El-Haddad MS, Selim OM. Priapism as a result of chronic myeloid leukemia: Case report, pathology, and review of the literature. J Sex Med 2015; 12:827-34.

7. Yoshida K, Kinoshita H, Taniguti H, Chizaki R, Nishida T, Kawakita $\mathrm{S}$, et al. Priapism complicated by chronic myelogenous leukemia (CML): A case report. Hinyokika Kiyo 2007; 53:323-5.

8. Tazi I. Priapism as the first manifestation of chronic myeloid leukemia. Ann Saudi Med 2009; 29:412.

9. Rojas B, Cabrera ME, Kliwadenko W, Avilés JJ. Priapism in a patient with chronic myeloid leukemia. Rev Med Chil 1998; 126:978-80.

10. Qureshi JM, Wood H, Feldman M. High flow priapism on color Doppler ultrasound. J Urol 2013; 189:2312-3. 